\title{
Gamifying Impromptu Speech for ESL/EFL Students
}

\author{
Girardelli, Davide $^{\mathrm{a}}$; Barroero, Patrizia ${ }^{\mathrm{b}}$ and Gu, Tingting ${ }^{\mathrm{b}}$ \\ ${ }^{a}$ School of Communication, Media \& Journalism, Wenzhou-Kean University, China; \\ ${ }^{\mathrm{b}}$ School of English Studies, Wenzhou-Kean University, China.
}

\begin{abstract}
This paper outlines an impromptu speech activity entitled "Dented Helmet vs. Spambot” intended as part of any introductory public speaking course. The activity is designed to overcome specific affective and cognitive challenges of ESL/EFL students, in particular Chinese learners, and is inspired by the principles of gamification (Kapp, 2012) with core gaming elements such as "freedom to fail", "rapid feedback", and "storytelling", The activity requires "Rory's Story Cubes" (a set of nine six-sided dice designed to spark creativity) and a special set of slides. An exploratory assessment of the effectiveness of our proposed activity was conducted on a sample of Chinese EFL sophomores enrolled in an international branch campus of a U.S. university in China, with 81 students completing our questionnaire. Overall, our findings provided some initial support to the effectiveness of our activity in terms of strenghtening students' ability to communicate orally "off the cuff", promoting students' understanding of the role of storytelling in effective presentations, fostering students' understanding of the major organizational formats used in organizing speeches, and increasing students' awareness of their nonverbal communication during oral presentations.
\end{abstract}

Keywords: Gamification; speaking skills; public speaking activity; impromptu speech; Chinese EFL students. 


\section{Introduction}

Chinese demand for English-based education is on the rise. China is not only the leading place of origin of international students in the U.S., but also the second largest importer of international branch campuses (IBCs). Out of the 29 IBCs currently active in China, 11 result from partnerships with U.S. educational institutions, making the United States the largest exporter of branch campuses in China. However, introducing American-style educational practices in China is in many ways challenging: Chinese students tend to be unwilling to communicate orally in class. This reticence is particularly problematic in activities that target students' speaking skills (Girardelli \& Patel, 2016).

The impromptu speech, namely "a speech delivered with little or no immediate preparation" (Lucas, 2005, p. 246), is probably the most intimidating activity. A first-level order of issues is based on emotional factors. The lack of (or very limited) wait-time has been found to be particularly anxiety-inducing in Chinese EFL students and may lead to inability or reluctance to speak as a result of such emotional pressure (Mak, 2011). This is coherent with Krashen's (1988) "affective filter hypothesis", which posits that emotional factors such as motivation, self-esteem, inhibition, and mistake-related anxiety may significantly influence students' outcomes and effective learning. A second-level order of issues is based on cognitive factors. Hsieh (2006) categorized the following problems confronted by Taiwanese students in impromptu speech competitions: 1) limited language skills (narrow knowledge of English vocabulary); 2) limited speaking skills (lack of skills directly related to public speaking, such as speech organization skills); 3) and limited background knowledge (limited life experience that is necessary to discuss about one topic).

In this paper, we describe an impromptu speech activity that has been designed to address typical issues of Chinese ESL/EFL students and present the results of an evaluation tool intended to capture Chinese students' experience and opinions regarding this new activity.

\section{Gamifying Impromptu Speech for ESL/EFL Students}

The proposed activity is entitled "Dented Helmet vs. Spambot" and has been inspired by the principles of gamification, namely the "application of game elements $[\ldots]$ in learning programs" (Kapp, 2012). In particular, our activity includes the following core game elements:

1. Freedom to fail: De-emphasis of grading concerns by assigning a baseline "participation grade"; focus on lessons learned through the gaming experience; 
2. Rapid feedback: Application of recently learnt concepts; multiple performance evaluations from both peers and instructors in a non face-threatening role playing context;

3. Storytelling: The activity is embedded in a unifying narrative. Participants are invited to contribute in developing a story with their speeches.

The use of gamification was intended to remedy ESL/EFL students' two levels of challenges: affective and cognitive. Affective factors are addressed by playing artificial roles in a fictional context. In this setting, ESL/EFL students can step outside the preestablished and potentially inhibiting student-instructor roles with relative codes and cultural conventions, while also saving face in case of mistakes. In addition, the activity addresses second-level, cognitive challenges in that it encourages the practice of certain organizational formats and it refers to areas with large background knowledge, such as super heroes, fairy tales, and other popular forms of fictional story telling. Because of the need of such mental stimulation paired with emotional comfort, the activity is expected to be challenging and rewarding for ESL/EFL students despite its simplifed aspects.The proposed gamified impromptu speech activity is intended as a part of any introductory public speaking course (see for instance Lucas, 2005), and its goals include:

- Goal 1: Building students' ability to communicate orally "off the cuff" with limited wait-time;

- Goal 2: Promoting students' understanding of the role of storytelling in effective presentations (vivid language, introduction/body/conclusion);

- Goal 3: Fostering students' understanding of the major organizational formats used in organizing speeches (cause/effect order; topical order; chronological order; spatial order; problem/solution order);

- Goal 4: Increasing students' awareness of their nonverbal communication during oral presentations (body language, paralanguage).

\section{1. “Dented Helmet vs. Spambot:” Gameplay}

The "Dented Helmet vs. Spambot" activity follows the format of popular music competition shows such as $X$-Factor with the instructor playing the part of the host. The class is subdivided into teams of a minimum 4 people in each team. One member of each team is selected as part of the judges. A list of presenters should be prepared in advance to ensure full participation. During each turn, one member from each team is called to give an impromptu speech. Judges should be provided with a score sheet at the beginning of the activity with the names of the presenters.

The activity requires: a) An overhead projector; b) "Rory's story cubes" (a set of 9 sixsided dice, each decorated with different images to spark creativity, see figure 1; 
Gamewright, 2010); and c) a set of "story slides" (figure 2) where three randomly selected Rory's story cubes are placed at the beginning of every turn (figure 3). The complete sets of slides for both the "Dented Helmet vs. Spambot" and the alternative, martial arts inspired "Black Belt Jones" impromptu speech activities are available upon request by contacting the first author.

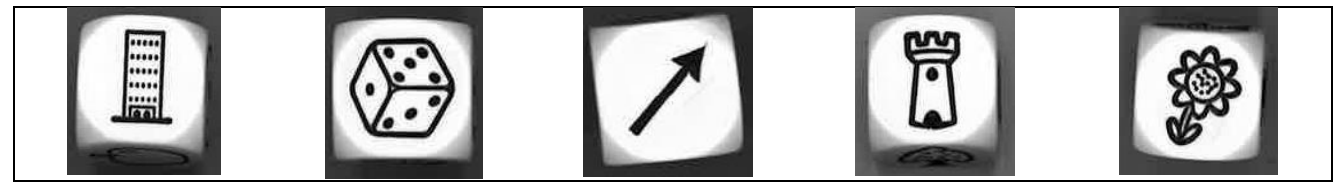

Figure 1. Example of images from “Rory's story cubes.” Source: Gamewright, 2010.

ACME Inc. will soon launch Gigabot, a new domestic robot, in the Chinese market. Gigabot comes equipped with three main features.

\section{The first feature is...}

The second feature is...

The thirst feature is...

Figure 2. Example of an "story slide"

\section{ACME Inc. will soon launch Gigabot, a new domestic robot, in the Chinese market. Gigabot comes equipped with three main features.}

\section{The first feature is... \\ The second feature is... \\ The thirst feature is...}

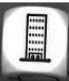

Figure 3. Example of an "story slide” with “"Rory's story cubes” (Gamewright, 2010) 
The instructor (host) introduces the activity clarifying the meaning of impromptu speech and introducing the judges, who are invited to evaluate the speeches of the presenters on a 1 to 3 scale, with 1 being ok, 2 being good, and 3 being excellent. The host then lists the characteristic of an excellent speech (see Lucas, 2005) in terms of effective body language (dominant posture, facing the audience, no "talking to the screen," open gestures, no defensive postures), eye contact (every member of the audience should be briefly included, no looking at ceiling/floor, no focus on only one part of the audience), and paralanguage (voice dynamics, no fillers). The host explains that participants will be also evaluated in their ability to complete their part of the "story" based on the "story slides" shown on the screen. There are no right or wrong answer; instead, presenters should create their own 2- to 3-minute narrative based on their imagination inspired by the "story slides".

The activity starts with a demonstrative "warm-up round" (figure 2 or figure 3 according to the chosen mode). The presenters can either create their own introduction or simply read the introduction available in the slide; then, they continue their speech following the pattern shown in the slide; finally, they are expected to end their performance with an original conclusion.

After the warm-up round, the actual activity begins. One member from each team is invited to leave the room. The host explains the basic premises of the story ("an endless fight between two archenemies") and places in the overhead projector the "story slide" for the first round. To add suspense, the host rolls the "Rory's story cubes" and randomly picks three dice to be placed in the "story slide". One by one, the presenters are invited to enter the room and to continue the story. At the end of each round, the host invites the judges to comment on each presenter's performance (they are expected to highlight at least one strength and one weakness) and to indicate the best presenter(s). After the judges' comments, the host invites the second group of presenters to exit the room, and so on and so forth, until the final "story slide."

\subsection{Debriefing and End of the Activity}

While a member of the jury computes the final score for each team, the host engages the entire audience, opening a discussion on the importance of nonverbal communication, effective organization, and vivid storytelling in successfull presentations. The host also introduces the organizational formats (chronological, spatial, cause-effect, topical, etc.; see Lucas, 2005) used in each "story slide". Following the principle of "rapid feedback" in gamification, participants receive during the activity an almost immediate feedback of their performance from their peer-judges in terms of both an overall score and suggestions on areas of strength and weakness. 


\section{Students' Evaluations of the Activity}

In this section we present an exploratory assessment of the effectiveness of our proposed activity on a sample of Chinese EFL sophomores enrolled in a Sino-American international branch campus accredited by the Middle States Commission on Higher Education. All core classes are taught in English. Sophomore students are required to take a basic public speaking course, which includes two impromptu speech activities ("Dented Helmet vs. Spambot" and "Black Belt Jones") with similar gameplay.

Data were collected on the $11^{\text {th }}$ week of the 15 -week semester during the course evaluation session. After completing the SIR II survey, students were administered a questionnaire with a set of additional questions that specifically targeted their experience in the impromptu speech activities. Participants were informed that their participation was voluntary. The instructor was not present during the evaluation process.

Respondents were asked to indicate their degree of agreement or disagreement with a total of 11 statements on a six-point Likert-type scale with "strongly disagree" coded as 1 , "disagree" as 2, "slightly disagree" as 3, "slightly agree" as 4, "agree" as 5, and "strongly agree" as 6. Following Mak's (2011) recommendation for similar samples of Chinese EFL students, a neutral point was not included in the scales to force respondents to commit themselves; in this manner we tried to avoid having most responses clustered in the neutral mid-point. Directions indicated: "Please be honest: your answers are completely anonymous. The following questions refer to the impromptu speech activities done during this semester".

\subsection{Participants}

A total of 81 students completed the questionnaire $(\mathrm{N}=117$; participation rate $=69.2 \%)$. Chinese Mandarin was the first language for the entire sample. $61.7 \%$ of the respondents were female, $38.3 \%$ were males. The vast majority of the participants were undergraduate sophomores majoring in accounting $(72.8 \%)$; the remaining sample included International Business (16\%), English (6.2\%), International Marketing (3.7\%) and Finance (1.2\%). Participants have been studying English for an average of $12 \frac{1}{2} 2$ years $(\mathrm{SD}=1.66)$.

\subsection{Findings}

Our preliminary findings (see table 1) based on students' evaluations suggest that the proposed gamified impromptu speech may be effective in reaching the intended goals. First, students perceived that the activity was "fun" (Q1: $\mathrm{M}=5.21, \mathrm{SD}=.68)$ and "well organized" $(\mathrm{Q} 2: \mathrm{M}=5.32, \mathrm{SD}=.72)$. Participants believed that the activity was "useful" (Q4: $\mathrm{M}=2.08, \mathrm{SD}=1.00 ; \mathrm{Q} 10: \mathrm{M}=1.86, \mathrm{SD}=1.14$ ) and provided some feedback to understand their own strengths $(\mathrm{Q} 7: \mathrm{M}=5.09, \mathrm{SD}=.79)$ and weaknesses $(\mathrm{Q} 8: \mathrm{M}=5.26$, $\mathrm{SD}=.67)$. Interestingly, the activity was in general perceived as slightly difficult (Q3: $\mathrm{M}=$ 
3.75, $\mathrm{SD}=1.31)$. It is, in fact, paramount that the task be challenging enough to be stimulating and in line with the overall objectives of a university level course. At the same time, it is equally vital that the structure of the activity should be easily graspable for the students to avoid potential interference with the overall communicative and linguistic exercise. In the spirit of "gamification", the topics in the activity should be familiar and amusing and the rules of the games straightforwardly explained by the instructor and understood by the students.

Table 1. Summary of findings.

\begin{tabular}{|c|c|c|}
\hline Statements & Mean & SD \\
\hline Q1. The impromptu speech activities were fun. & 5.21 & .68 \\
\hline Q2. The impromptu speech activities were well organized. & 5.32 & .72 \\
\hline Q3. The impromptu speech activities were difficult. & 3.75 & 1.31 \\
\hline Q4. The impromptu speech activities were useless & 2.08 & 1.00 \\
\hline $\begin{array}{l}\text { Q5. The impromptu speech activities helped me to understand } \\
\text { how to organize my speech. }\end{array}$ & 5.10 & .83 \\
\hline $\begin{array}{l}\text { Q6. The impromptu speech activities helped to understand the } \\
\text { importance of nonverbal communication. }\end{array}$ & 5.05 & .96 \\
\hline $\begin{array}{l}\text { Q7 The impromptu speech activities helped me to understand my } \\
\text { strengths as a public speaker. }\end{array}$ & 5.09 & .78 \\
\hline $\begin{array}{l}\text { Q8. The impromptu speech activities helped me to understand my } \\
\text { weaknesses as a public speaker. }\end{array}$ & 5.26 & .67 \\
\hline $\begin{array}{l}\text { Q9. The impromptu speech activities helped me to understand } \\
\text { the major organizational formats in public speaking (topical, } \\
\text { cause/effect, chronological, spatial, ecc.). }\end{array}$ & 5.07 & .83 \\
\hline Q10. The impromptu speeches activities were a waste of time. & 1.86 & 1.14 \\
\hline $\begin{array}{l}\text { Q11. The impromptu speech activities helped me to become more } \\
\text { confident in giving a short speech in English without much } \\
\text { preparation. }\end{array}$ & 5.04 & 1.07 \\
\hline
\end{tabular}

Regarding goal 1, namely "building students' ability to communicate orally "off the cuff" with limited wait time", our participants perceived that this activity provided a contribution in increasing their confidence in giving a short speech in English without much preparation (Q11: $\mathrm{M}=5.04, \mathrm{SD}=1.07)$. Our findings also suggest that students felt that the activity promoted their understanding of the role of effective "storytelling" in effective 
presentations (goal 2) by strenghtening their ability to organize their speeches (Q5: $\mathrm{M}=$ 5.10 , SD = .83). Goal 3 involved fostering students' understanding of the major organizational formats used in organizing speeches (cause/effect order; topical order; chronological order; spatial order; problem/solution order): also in this case, our sample perceived that the activity was beneficial (Q9: $\mathrm{M}=5.07, \mathrm{SD}=.83$ ). Regarding goal 4, our findings suggest that the activity contributed in increasing students' awareness of the importance of nonverbal communication (Q6: $\mathrm{M}=5.05, \mathrm{SD}=.96)$.

\section{Conclusion}

In this paper we have outlined an impromptu speech activity designed to overcome specific affective and cognitive challenges of ESL/EFL students by implementing the principles of gamification (Kapp, 2012). The activity appeared to be effective in strengthening students' ability to communicate orally "off the cuff", promoting students' understanding of the role of storytelling in effective presentations, fostering students' understanding of the major organizational formats used in organizing speeches, and increasing students' awareness of their nonverbal communication in presentational settings. Additional research is still required to demonstrate the effectiveness of our gamified activities both in absolute terms and in comparison with other treatments intended to overcome specific affective and cognitive challenges of ESL/EFL students.

\section{References}

Girardelli, D., \& Patel, V. (2016). The theory of planned behavior and Chinese EFL students' in-class participation. Journal of Language Teaching and Research, 7(1), 3141.

Hsieh, S. M. (2006). Problems in preparing for the English impromptu speech contest. Regional Language Centre Journal, 37(2), 216-235.

Kapp, K. M. (2012). Games, gamification, and the quest for learner engagement. $T+D$, 66(6), 64-88.

Krashen, S. D. (1988). Second language acquisition and second language learning. Prentice-Hall International.

Lucas, S. E. (2005). The art of public speaking (Tenth edition). Boston, MA: McGraw-Hill.

Mak, B. (2011). An exploration of speaking-in-class anxiety with Chinese ESL learners. System, 39, 202-214.

Gamewright (Firm). (2010). Rory's story cubes: Let your imagination roll wild!. Newton, MA: Gamewright. 